\title{
Spontaneous spondylodiscitis: review, incidence, management, and clinical outcome in 44 patients
}

\author{
Ghada Waheed, MSc, ${ }^{1}$ Mohamed A. R. Soliman, MSc, ${ }^{2}$ Ahmed M. Ali, MD, ${ }^{2}$ and \\ Mohamed H. Aly, MD2 \\ 1Shark Al Madina Hospital, Ministry of Health, Alexandria; and ${ }^{2}$ Neurosurgery Department, Cairo University, Cairo, Egypt
}

OBJECTIVE Spontaneous spondylodiscitis remains uncommon but is a serious complication of the vertebral column. Risk factors include diabetes, hemodialysis, intravenous drug abuse, and chronic steroid use, and pain is the most common presenting symptom. This study aims to review the literature and report on the incidence, management, and clinical outcome of spontaneous spondylodiscitis in 44 patients.

METHODS This is a prospective study including 44 patients with spontaneous spondylodiscitis managed in the neurosurgery department of Cairo University Hospitals during the period between January 2012 and October 2017. All patients had a full clinical assessment, laboratory tests, radiological studies in the form of MRI with and without contrast, and a postoperative follow-up of up to 12 months.

RESULTS Twelve cases underwent conservative treatment in the form of complete bed rest, intravenous antibiotics, and a spinal brace. Ten cases underwent surgical intervention in the form of laminectomy, debridement, and open biopsy. Twenty-two cases underwent laminectomy and surgical stabilization with fusion. There were 15 cases of tuberculous spondylodiscitis, 6 cases of brucellosis, 6 cases of pyogenic infection, and 17 cases in which no organism could be detected.

CONCLUSIONS Once the primary diagnosis is confirmed, early and adequately prolonged antibiotic therapy is recommended for spontaneous spondylodiscitis. Some cases can be successfully treated with conservative treatment alone, whereas surgery may be needed in other cases such as severe destruction of endplates, spinal abscess formation, mechanical instability, neurological deficits, and severe pain that have failed to respond to conservative treatment.

https://thejns.org/doi/abs/10.3171/2018.10.FOCUS18463

KEYWORDS spontaneous spondylodiscitis; conservative treatment; laminectomy; surgical fusion

$\mathrm{S}$ PONDYLODISCITIS is an inflammatory disease that affects the spine, discs, and paraspinal tissue. Spontaneous spondylodiscitis represents $3 \%-5 \%$ of all cases of osteomyelitis. ${ }^{13}$ The worldwide incidence is estimated at 4-24 cases/million inhabitants/year. ${ }^{13,38}$ There has been an increase in its incidence in the past few years because of better diagnostic tests, the resurgence of tuberculosis (TB), the use of intravenous (IV) drugs, the increase in immunocompromised patients, and the rise in bacteremia and iatrogenic infections. ${ }^{6,38}$ The tuberculous spine infection was first described by Pott in 1779, whereas the pyogenic spine infection was first described by Lannelongue in $1879 .^{12,24}$ The first series of pyogenic cases was published by $\mathrm{Ku}-$ lowski in $1936 .{ }^{19}$

Spondylodiscitis tends to initially affect the disc, then spread to the vertebral endplates, and in turn can spread to the paraspinal tissues. ${ }^{10}$ Spondylodiscitis can be classified as pyogenic, granulomatous, and parasitic/fungal. Currently, TB is the most common cause (around 50\% of worldwide cases), followed by pyogenic agents, whereas the parasitic and fungal cases are rare. ${ }^{6,10,20,38}$ The sources of infection include hematogenous spread from another

ABBREVIATIONS ASIA = American Spinal Injury Association; CRP = C-reactive protein; DVT = deep vein thrombosis; ESR = erythrocyte sedimentation rate; IV = intravenous; TB = tuberculosis; $\mathrm{WBC}=$ white blood cell. 
site, possible contiguous infection, and exterior inoculation. The most common hematogenous pyogenic organism is Staphylococcus, which frequently affects the lumbar vertebrae and, to a lesser extent, the cervical and thoracic levels; tuberculous spondylodiscitis primarily affects the thoracic vertebrae (commonly multilevel or multifocal). ${ }^{17}$ The contiguous spread of spondylodiscitis is generally considered polymicrobial. $6,10,38$

As the clinical picture usually lacks specific symptoms or signs, there tends to be an average delay of 2-6 months before a definitive diagnosis is established. 2,4,6,28,29 This can lead to a poorer prognosis and undesirable morbidity. ${ }^{6}$ Therefore, physicians must suspect the diagnosis of spondylodiscitis based on clinical symptoms and signs such as fever, localized pain, and spinal deformity. Moreover, if spondylodiscitis is suspected clinically, it must be confirmed by laboratory tests such as white blood cell (WBC) count, erythrocyte sedimentation rate (ESR), and C-reactive protein (CRP), which tend to increase. ${ }^{15,16}$ Blood culture tests tend not to show a good diagnostic yield. ${ }^{15}$ The imaging modality of choice for the diagnosis of spondylodiscitis is MRI with contrast because of its high specificity and sensitivity, as well as its ability to differentiate infections, neoplasms, and degenerative changes and provide good anatomical information for surgical planning., ${ }^{6,29,38}$

In the past few decades, death and morbidity from spondylodiscitis have dramatically improved due to advances in the diagnostic techniques as well as antimicrobial and surgical treatments. ${ }^{6,10,29}$ Antimicrobial treatment is the therapy of choice, and its goal is to eradicate the infection, decrease pain, and preserve and restore the structure and function of the vertebral column. Prolonged combination antimicrobial therapy is essential even when surgical intervention is indicated. In tuberculous spondylodiscitis, the recommended regimen is a combination of 6 months of rifampicin and isoniazid with ethambutol and pyrazinamide for the first 2 months. ${ }^{27}$ For pyogenic spondylodiscitis, the recommended regimen is parenteral antibiotics for 3-8 weeks, followed by oral antibiotic for $6-12$ weeks depending on the antibiogram, the germ isolated, and the patient's characteristics. ${ }^{4,21,27}$ There is no clear role for combined antibiotic therapy in pyogenic spondylodiscitis, although it tends to be given after instrumentation (e.g., rifampicin combined with quinolones). ${ }^{39}$ Titanium is the implant material of choice because it is very difficult for bacterial biofilm to develop on the titanium compared to other materials. ${ }^{25}$

Perioperative complications are very common, especially in patients with serious comorbidities and an advanced age. Postsurgery mortality tends not to be less than $4 \%$ according to multiple series. ${ }^{18,32,35}$ Early complications include but are not limited to wound infection, wound dehiscence, need for repeat debridement, bacteremia, and neurological deterioration. Late complications include but are not limited to persistent deep tissue infection, progressive deformity, chronic pain, fusion failure, and fracture or resorption of the implants. ${ }^{4,6,29}$

Until now, spondylodiscitis and its management have not been studied in a clinical trial, and information about this disease has come from retrospective case series and isolated cases. In this study, we present our prospectively collected patient clinical and management data, and we provide recommendations for the management of spondylodiscitis.

\section{Methods}

This prospective cohort study was conducted on a series of spontaneous spondylodiscitis patients from our referral area. All patients were treated between January 2012 and October 2017 in the neurosurgery department at Cairo University Hospitals, which is the biggest referral tertiary care center in Egypt. Cairo University Hospitals are public hospitals whose referral area has a population of nearly 20.5 million. Note that there is only one other smaller university hospital with a neurosurgery department and that the other medical departments do not treat spine infections. However, there is a private sector in Egypt that treats patients who can afford surgical expenses. Post-spinal surgery infections and patients lost to follow-up were excluded from the study. Cases of spontaneous spondylodiscitis were defined as patients with clinical (fever, localized pain, and/or neurological defect), radiological (images of vertebral or disc impairment and/ or a paraspinal collection compatible with spondylodiscitis on spinal MRI), and laboratory (increased WBC, CRP, and ESR) findings compatible with spondylodiscitis and confirmed by disc cultures and vertebral material cultures or other infection source material cultures (e.g., blood cultures). In some cases, we could not obtain a positive culture, so empirical antibiotic treatment was started and maintained according to subsequent clinical, radiological, and laboratory findings. Surgery was indicated for patients who presented with progressive or acute neurological deficit, epidural extension with compression of the spinal cord or nerve roots, evidence of spinal instability or deformity, progressive clinical or radiological deterioration despite adequate antimicrobial treatment, and failure of mobilization in orthosis due to severe pain. Generally, once the clinical and radiological diagnoses were established and the above surgical indication criteria were met, the decision was made to proceed with surgery via laminectomy and debridement or internal fixation, as well as to take cultures from the infected tissues.

\section{Surgical Techniques}

\section{Laminectomy and Debridement}

After induction of general anesthesia, the patient was placed prone, and a laminectomy was performed with decompression of the nerve roots and thecal sac, followed by debridement of purulent or inflammatory collections in the paraspinal and epidural space, and cultures were taken from the purulent or inflamed materials.

\section{Posterior Spinal Fusion}

In addition to the above procedure, posterior transpedicular fusion with titanium screws and rods was performed. If the patient's own bone did not appear infected, it was used in the fusion. Wound drains were left for 5 days postoperatively for antibiotic lavages, according to the culture and sensitivity findings. 
TABLE 1. Post-management outcome definitions

\begin{tabular}{|c|c|}
\hline Outcome & Definition \\
\hline Cure & $\begin{array}{l}\text { Pain free or minimal pain permitting normal daily } \\
\text { activities w/ no evidence of spine instability or radio- } \\
\text { graphic progression }\end{array}$ \\
\hline Improvement & $\begin{array}{l}\text { Marked decrease in pain intensity as well as improve- } \\
\text { ment in the pre-management of neurological deficit } \\
\text { if present }\end{array}$ \\
\hline Stabilization & Pain improvement w/ no neurological improvement \\
\hline Deterioration & Neurological deterioration \\
\hline
\end{tabular}

\section{Patient Analysis and Follow-Up}

Once the patients were discharged, they were assessed and followed up in the outpatient neurosurgery clinic. The post-management outcome was defined according to Table 1 . The radiographic cure criteria were as follows: spinal fusion of the affected segment with the absence of significant local pain, proper instrumentation position, and absence of breakage or displacement of instrumentation.

\section{Statistical Analysis}

A descriptive statistical analysis of the cohort was done, at all times guaranteeing confidentiality of the clinical data.

\section{Results \\ Demographics and Causative Organisms}

In the period between January 2012 and October 2017, the neurosurgery department at Cairo University Hospitals treated 44 consecutive patients with a diagnosis of spontaneous spondylodiscitis. Patients had a median age of 41.3 years (range 13-65 years), and there was a slight male predominance (59.1\%; Table 2). All the patients presented with local pain in the spine, which was more pronounced over the affected level, and only $54.5 \%$ had a fever at the time of presentation. There was more than 4 months' delay in the diagnosis (from the start of symptoms to reaching a definitive diagnosis). On presentation, $34.1 \%$ of the patients had a neurological deficit, most of whom presented with motor weakness (11 patients with American Spinal Injury Association [ASIA] grade D and 4 patients with ASIA grade C). Microbiological confirmation of the spondylodiscitis was obtained in $61.4 \%$ of the patients. Mycobacterium tuberculosis was the most frequent organism isolated (15 patients), followed by pyogenic infection (6 patients with brucellosis, 3 with Staphylococcus aureus, and 3 with streptococcal infection; Table 3). Despite performing multiple cultures, we failed to obtain microbiological confirmation in 17 cases (38.6\%).

\section{Laboratory Findings}

On admission, the ESR was elevated in all the patients except 4 with Pott's disease and 1 patient with brucellosis and ranged from 4 to $145 \mathrm{~mm}$ with a mean of $64.3 \mathrm{~mm}$ in the first hour. The mean bacterial spondylodiscitis ESR $(82.5 \mathrm{~mm}$, range $29-145 \mathrm{~mm}$ ) was nearly double the mean tuberculous ESR (39.7 mm, range 4-108 mm). The CRP
TABLE 2. Summary of characteristics in 44 patients with spontaneous spondylodiscitis

\begin{tabular}{lc}
\hline \multicolumn{1}{c}{ Variable } & Value \\
\hline Median age in yrs (range) & $41.3(13-65)$ \\
\hline Sex, no. & 26 \\
\hline Males & 18 \\
\hline Females & \\
\hline Clinical presentation, no. (\%) & $44(100)$ \\
\hline Local pain & $24(54.5)$ \\
\hline Fever & $15(34.1)$ \\
\hline Neurological deficit, no. (\%) & $4(9.1)$ \\
\hline ASIA grade C & $11(25)$ \\
\hline ASIA grade D & 12 \\
\hline Levels involved, no. & 26 \\
\hline Thoracic & 6 \\
\hline Lumbar & $12(27.3)$ \\
\hline Multilevel & $10(22.7)$ \\
\hline Management, no. (\%) & $22(50)$ \\
\hline Conservative &
\end{tabular}

level was high (mean $25.7 \mathrm{mg} / \mathrm{dl}$, range 6-98 mg/dl) in all the patients but began to decrease 2 weeks after initiation of treatment and was a good indicator of treatment response. The WBC count was the least sensitive laboratory test (range 5000-19,000) and was elevated in only 16 patients.

\section{Management}

Twelve cases were managed conservatively through complete bed rest, IV antibiotics for 6 weeks followed by oral antibiotics for another 6 weeks, and a spinal brace. Empirical antibiotics were given in the form of a combination of ceftriaxone, metronidazole, and vancomycin covering the gram-positive, gram-negative, and anaerobic bacteria. In cases in which Pott's disease was suspected, patients were treated with a combination of 6 months of rifampicin and isoniazid with ethambutol and pyrazinamide for the first 2 months. In the patients with confirmed brucellosis, a combination of doxycycline and rifampin was given for 8 weeks. Ten cases underwent surgical intervention in the form of laminectomy, debridement, and open biopsy. In 9 of these 10 cases, we were able to obtain an etiological diagnosis (4 TB, 2 brucellosis, 2 S. aureus, and 1 Streptococcus), so the biopsy net diagnostic yield was $90 \%$. Twenty-two cases underwent laminectomy and surgical stabilization with fusion. In 18 of these 22 cases, an etiological diagnosis was obtained (11 TB, 4 brucellosis, 2 streptococci, and $1 S$.aureus), so the culture net diagnostic yield was $81.8 \%$. Fusion was indicated in cases with radiological deformity or instability.

Among cases with spontaneous spondylodiscitis in the thoracic area (12 cases), 9 improved, 2 stabilized, and 1 deteriorated by the 3-month follow-up. At the 12-month follow-up, 7 cases were considered cured, 3 had improved, 
TABLE 3. Characteristics of different types of infection

\begin{tabular}{|c|c|c|c|c|}
\hline \multirow[b]{2}{*}{ Variable } & \multicolumn{4}{|c|}{ Causative Organism } \\
\hline & TB & Brucellosis & Staphylococcus aureus & Streptococcus \\
\hline No. of pts & 15 & 6 & 3 & 3 \\
\hline Mean age, yrs & 40.8 & 32.5 & 53.3 & 60 \\
\hline Location & Dorsal 5, lumbar 10 & Dorsal 3, lumbar 3 & Dorsal 1, lumbar 1, multilevel 1 & Dorsal 1, lumbar 1, multilevel 1 \\
\hline $\begin{array}{r}\text { Mean hospital } \\
\text { stay in days }\end{array}$ & 11.9 & 12.8 & 30 & 31.3 \\
\hline Morbidity & $\begin{array}{l}2 \text { cases } w / \text { intraop bleeding requiring blood } \\
\text { transfusion, } 1 \text { conservatively treated case } \\
\text { that developed neurological deterioration } \\
\text { requiring laminectomy }\end{array}$ & $\begin{array}{l}\text { Misdirected screw, } \\
\text { needed revision }\end{array}$ & $\begin{array}{l}1 \text { case w/ wound dehiscence, } \\
1 \text { case } w / \text { intraop bleeding } \\
\text { requiring blood transfusion }\end{array}$ & $\begin{array}{l}1 \text { case w/ DVT, } 1 \text { case w/ } \\
\text { intraop bleeding requiring } \\
\text { blood transfusion }\end{array}$ \\
\hline Mortality & None & None & 1 & None \\
\hline
\end{tabular}

pts $=$ patients

1 was stable, and 1 death had occurred. Among cases with spondylodiscitis in the lumbosacral area (26 cases), 22 improved, 3 stabilized, and 1 deteriorated by the 3-month follow-up; at the 12-month follow-up, 18 cases were considered cured, 5 had improved, 2 were stable, and 1 had deteriorated. Among the multilevel dorsolumbar cases (6 cases), 3 improved, 2 deteriorated, and 1 stabilized by the 3-month follow-up; at the 12-month follow-up, 3 were cured, 1 had improved, 1 had stabilized, and 1 death had occurred. Therefore, the cure rate in lumbosacral spondylodiscitis was 69.2\%; in dorsal spondylodiscitis, 58.3\%; and in multilevel spondylodiscitis, 50\%. After combined surgery and antimicrobial treatment, 31 patients (96.9\%) experienced improvement or stabilization and 1 patient deteriorated and then died from septicemia. As regards the conservatively managed group, $10(83.3 \%)$ of the 12 patients improved or stabilized, 1 patient neurologically deteriorated acutely, and 1 patient died from septicemia.

\section{Peri-Management Complications}

Complications during and after management required reoperation and fusion in 2 laminectomy cases because of uncontrollable pain and consisted of wound dehiscence in 1 case and postoperative anemia requiring blood transfusion in 4 cases. Acute neurological deterioration occurred in 2 patients in the conservative treatment group, one who underwent laminectomy and debridement with no improvement of their neurological status and the other who died from septicemia. Two patients developed deep vein thrombosis (DVT; one in the conservative treatment group and the other in the laminectomy group). Moreover, 1 patient in the fusion group had severe sciatica postsurgery, and follow-up CT showed a misdirected screw, which needed revision. The average hospital stay was 23 days (range 9-68 days). After excluding the dead patients, we calculated a mean follow-up period of 16.4 months.

The mortality rate in our series was $4.5 \%$ : a 63 -year-old female with ASIA grade $\mathrm{C}$ who was treated conservatively with antibiotics but succumbed to septicemia, multiorgan failure, and finally death on day 16 postadmission; and a 41-year-old male with ASIA grade D who was treated with decompression and fusion but died from septicemia and multiorgan failure on day 14 postadmission.

\section{Discussion}

This spontaneous spondylodiscitis series is the third largest in terms of the number of patients in the last 5 years and it demonstrates a higher incidence of TB and brucellosis among communities in which IV drug abusers are not common. Also, this study is unique in its prospective nature. In Table 4, we compare our data with recently published studies on spontaneous spondylodiscitis. ${ }^{3,7,9,18,22,23,30-34,36}$ Compared to other series, our study had a mean patient age that was younger by more than 10 years, $27 \%$ of our patients were managed conservatively, only $8.3 \%$ of the conservatively managed patients required surgery, and 30-day overall mortality was less than 5\%. Our series is similar to the other series in its male predominance.

\section{Diagnosis of the Cause of Spondylodiscitis and the Predisposing Factors}

In order to achieve a favorable functional outcome and to minimize spinal deformity and chronic pain, a lot of effort must be focused on early detection of the frequently poorly diagnosed spontaneous spondylodiscitis. ${ }^{1,4,6}$ In the Zimmerli study, only $5 \%$ of patients with vertebral involvement with $S$. aureus were correctly diagnosed on admission. ${ }^{38}$ As regards the causative organism, in our series, $M$. tuberculosis was the most commonly observed organism. It is well known that Pott's disease badly deforms the spine, even if the disease is correctly treated medically, and surgical stabilization of the spine is now recommended. ${ }^{26}$ However, 4 TB patients in our series were managed with only laminectomy and open biopsy without any form of fixation, and they did not progress to any kind of deformity on long-term follow-up. The mean hospital stay for the TB patients was the shortest (11.9 days), followed by that for the brucellosis group (12.8 days) and those for the staphylococci (30 days) and streptococci (31.8 days) groups (Table 3). The risk factors for spondylodiscitis include distant infection site, advanced age, diabetes mellitus, IV drug use, immunosuppression, HIV infection, cancer, chronic kidney disease, and liver cirrhosis. ${ }^{1,11}$ However, in our series, there were only 4 patients with uncontrolled diabetes and 4 with a distant source of infection; the rest 
TABLE 4. A review of the literature on spondylodiscitis published in the last 5 years

\begin{tabular}{|c|c|c|c|c|c|c|}
\hline $\begin{array}{l}\text { Authors } \\
\& \text { Year }\end{array}$ & $\begin{array}{l}\text { No. of } \\
\text { Pts }\end{array}$ & $\begin{array}{l}\text { Spinal Levels } \\
\text { Involved }\end{array}$ & $\begin{array}{l}\text { Causative } \\
\text { Organisms }\end{array}$ & CT-Guided Biopsy & Treatment & Outcome \\
\hline $\begin{array}{l}\text { Yang et al., } \\
2014\end{array}$ & 32 & Lumbar & $\begin{array}{l}\text { Pyogenic (26), } \\
\text { TB (1), fungal } \\
\text { (1) }\end{array}$ & - & $\begin{array}{l}\text { Endoscopic percutaneous decom- } \\
\text { pression \& dilute Betadine irrigation }\end{array}$ & Pain improvement (84.4\%) \\
\hline $\begin{array}{l}\text { Shiban et } \\
\quad \text { al., } 2014\end{array}$ & 17 & $\begin{array}{l}\text { Cervical, tho- } \\
\text { racic, lumbar }\end{array}$ & Pyogenic & Positive in $1 \mathrm{pt}$ & Decompression \& instrumentation & $\begin{array}{l}\text { Neurological improvement } \\
(72.7 \%)\end{array}$ \\
\hline $\begin{array}{r}\text { Devkota et } \\
\text { al., } 2014\end{array}$ & 37 & $\begin{array}{l}\text { Dorsolumbar, } \\
\text { lumbar }\end{array}$ & Pyogenic & - & Decompression \& fusion w/ iliac crest & $\begin{array}{l}\text { Good fusion radiologically in } \\
\text { most cases }\end{array}$ \\
\hline $\begin{array}{l}\text { Bydon et } \\
\quad \text { al., } 2014\end{array}$ & 118 & $\begin{array}{l}\text { Cervical, } \\
\text { thoracic, lum- } \\
\text { bosacral }\end{array}$ & Pyogenic & - & $\begin{array}{l}\text { Decompression \& fixation (69.5\%), } \\
\text { decompression }(30.5 \%)\end{array}$ & $\begin{array}{l}\text { Infection persistence }(9 \%) \\
\quad \text { redo surgery }(17 \%)\end{array}$ \\
\hline $\begin{array}{l}\text { Mohamed } \\
\text { et al., } \\
2014\end{array}$ & 15 & $\begin{array}{l}\text { Cervical, tho- } \\
\text { racic, lumbar }\end{array}$ & Pyogenic & - & $\begin{array}{l}\text { Decompression \& pst fixation }(73.3 \%) \\
\text { combined ant \& pst fixation }(6.7 \%)\end{array}$ & $\begin{array}{l}\text { Ambulating }(46.7 \%) \text {, ambulat- } \\
\text { ing w/ assistance }(40 \%) \\
\text { bedridden }(6.7 \%)\end{array}$ \\
\hline $\begin{array}{l}\text { Chen et al., } \\
\quad 2015\end{array}$ & 13 & $\begin{array}{l}\text { Thoracic, upper } \\
\text { lumbar }\end{array}$ & $\begin{array}{l}\text { Pyogenic (8), TB } \\
\text { (1), fungal (1) }\end{array}$ & $\begin{array}{l}\text { Done in all cases } \\
\text { (before proce- } \\
\text { dure) }\end{array}$ & Endoscopic percutaneous drainage & Pain improvement (100\%) \\
\hline $\begin{array}{r}\text { Tschöke et } \\
\text { al., } 2015\end{array}$ & 18 & Lumbar & Pyogenic & - & TLIF \& pst fixation & Pain improvement (100\%) \\
\hline $\begin{array}{l}\text { Shetty et } \\
\text { al., } 2016\end{array}$ & 27 & Lumbar & Pyogenic & - & TLIF \& pst fixation & $\begin{array}{l}\text { Excellent outcome }(51.9 \%) \text {, } \\
\text { good outcome }(33.3 \%) \text {, } \\
\text { fair outcome }(11.1 \%), \text { poor } \\
\text { outcome }(3.7 \%)\end{array}$ \\
\hline $\begin{array}{l}\text { Kothari et } \\
\text { al., } 2016\end{array}$ & 20 & $\begin{array}{l}\text { Cervical, tho- } \\
\text { racic, lumbar }\end{array}$ & TB & - & $\begin{array}{l}\text { Decompression \& fusion (ant or pst) } \\
(95 \%), \text { pst decompression }(5 \%)\end{array}$ & $\begin{array}{l}\text { High rate of mortality associ- } \\
\text { ated w/ preop immobility }\end{array}$ \\
\hline $\begin{array}{l}\text { Turel et al., } \\
2017\end{array}$ & 7 & $\begin{array}{l}\text { Thoracic, } \\
\text { lumbar }\end{array}$ & Pyogenic & $\begin{array}{l}\text { Positive cultures } \\
\text { obtained }(85.7 \%)\end{array}$ & MI decompression \& discectomy & $\begin{array}{l}4.4 \text { points pain improvement } \\
\text { on VAS }\end{array}$ \\
\hline $\begin{array}{l}\text { Martín- } \\
\text { Alonso, } \\
2018\end{array}$ & 83 & $\begin{array}{l}\text { Cervical, } \\
\text { thoracic, lum- } \\
\text { bosacral }\end{array}$ & $\begin{array}{l}\text { Pyogenic (39), } \\
\text { TB (18), } \\
\text { fungal (1) }\end{array}$ & $\begin{array}{l}\text { Done for inflamma- } \\
\text { tory or infectious } \\
\text { tissue }\end{array}$ & $\begin{array}{l}\text { Laminectomy \& biopsy (21.7\%), pst } \\
\quad \text { fusion }(42.2 \%) \text {, ant fusion }(33.7 \%)\end{array}$ & $\begin{array}{l}\text { Improvement }(86.7 \%) \text {, stabili- } \\
\text { zation }(9.6 \%) \text {, deterioration } \\
(2.4 \%)\end{array}$ \\
\hline $\begin{array}{l}\text { Current } \\
\text { series }\end{array}$ & 44 & $\begin{array}{l}\text { Thoracic, } \\
\text { lumbar }\end{array}$ & $\begin{array}{l}\text { TB (15), } \\
\text { pyogenic (6), } \\
\text { brucellosis (6) }\end{array}$ & - & $\begin{array}{l}\text { Conservative (27.3\%), decompression } \\
(22.7 \%) \text {, decompression \& fusion } \\
(50 \%)\end{array}$ & $\begin{array}{l}\text { Improvement \& stabilization in } \\
\text { conservative group } 83.3 \% \text {, } \\
\text { in surgical group } 96.9 \%\end{array}$ \\
\hline
\end{tabular}

ant = anterior; $\mathrm{MI}$ = minimally invasive; $\mathrm{pst}$ = posterior; TLIF = transforaminal lumbar interbody fusion; VAS = visual analog scale.

of the patients were immunocompetent. This confirms that $\mathrm{TB}$, which is the most commonly isolated organism in our series, can occur in any exposed immunocompetent individual. $^{10,26}$

\section{Clinical Presentation}

Most authors describe pain as one of the initial symptoms, and $100 \%$ of our patients presented with back pain as the initial symptom. ${ }^{11}$ Fever in the days or weeks preceding admission is also a presenting symptom but is less common than pain. ${ }^{17}$ Fever was observed in only $54.5 \%$ of our series. When seeing a patient with progressive back pain, a certain degree of suspicion is needed, and we recommend that physicians refer the patients for MRI for early diagnosis of the infection.

\section{Management Workflow}

Once we diagnosed a patient via MRI of the spine, a complete workup was done by taking a proper patient history to ascertain possible risk factors and by conducting tests of WBC, ESR, CRP, and blood cultures, and if there was any question about a cardiac source, a transesophageal echocardiography was done. If any pathogen was detected, antibiotics were administered according to culture and sensitivity findings. Otherwise, broad-spectrum IV antibiotics were administered for 6 weeks, followed by 6 weeks of oral antibiotics and a spinal brace. Surgery was indicated only if there was spinal cord compression (e.g., epidural abscess); neurological symptoms such as numbness, radicular pain, weakness, or sphincter problems; failure of the broad-spectrum antibiotics to improve symptoms and laboratory markers after 6 weeks of treatment; or an unstable spine. We could not perform CT-guided biopsy at our institute as it was not available; however, we know that it is recommended nowadays, as it provides confirmation samples of the causative organism. ${ }^{22}$ In all cases in which surgery was indicated, antibiotics were not administered until after obtaining intraoperative cultures.

\section{Clinical, Laboratory, and Radiological Follow-Up}

In our cases, we found that the absence or improvement 


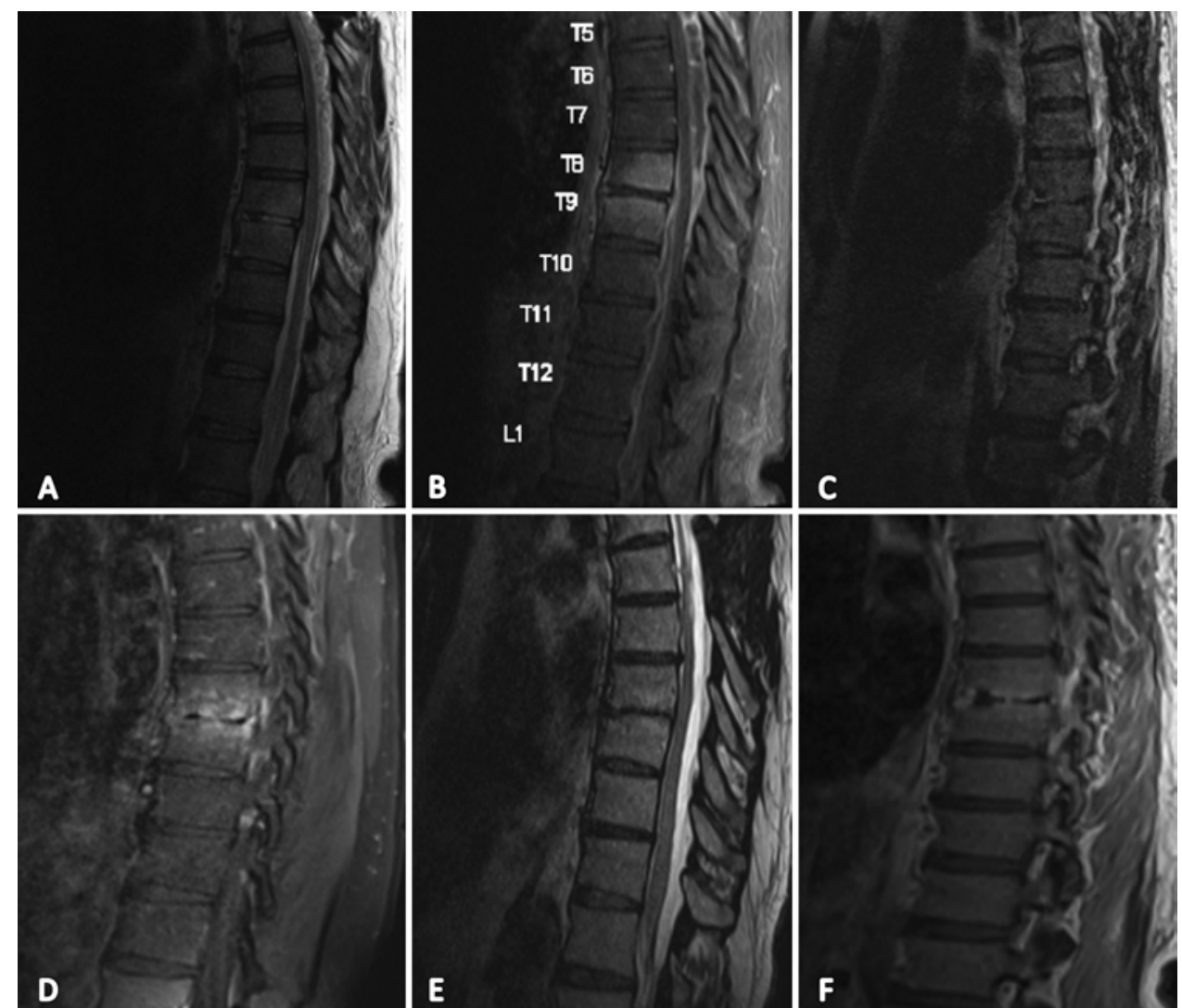

FIG. 1. Sagittal MRI studies of the thoracic spine with and without contrast obtained in a patient with tuberculous spondylodiscitis. A: Preoperative T2-weighted sequence showing high-intensity signal in the T7-8 disc space and surrounding inflammatory changes in the adjacent vertebrae. B: Preoperative T1-weighted sequence with contrast showing enhancement of the epidural collection and the adjacent vertebral bodies. C and D: Twelve-week postoperative T2- and T1-weighted sequences with contrast showing more destructive changes in the endplate than on the preoperative images despite clinical improvement. $\mathrm{E}$ and F: Sixmonth postoperative T2- and T1-weighted sequences with contrast showing improvement of the inflammatory changes in the disc space and adjacent vertebral bodies.

of pain is the best indicator of a cure, even if the early posttreatment MR images showed stable or worsening findings, and this is consistent with findings in the literature. ${ }^{37}$ We used to perform routine MRI at 12 weeks and 6 months after treatment initiation; however, we found that the 12-week MRI study was not a helpful indicator of successful treatment even though its findings were worse than the pretreatment MRI study in 8 cases. In all cases, however, improvement or even complete cure was demonstrated on the 6-month MRI study (Figs. 1 and 2). Concerning the laboratory tests (ESR, CRP, and WBC), they were helpful in the diagnosis when infection was suspected, but they have low specificity to confirm the diagnosis. They were also helpful, especially the CRP, to follow up on the progression of treatment. ${ }^{5,15,16} \mathrm{We}$ also found that the ESR in the first hour in bacterial spondylodiscitis was approximately double the ESR in tuberculous spondylodiscitis. The WBC count did not have any significant value in our study. Carragee et al. observed normalization of the CRP levels within 3 months of the initiation of treatment and a good prognosis when the ESR dropped to $25 \%$ of its initial value. ${ }^{5}$ In our series, all the patients' CRP levels were progressively dropping except in one patient who was on broad-spectrum antibiotics and turned out to have a tuberculous infection.

\section{Antibiotic Treatment, Decompression, and Instrumented Fusion}

The most important factor in managing spontaneous spondylodiscitis is treatment of the causative organism. This was achieved using prolonged antibiotic treatment. If there was no indication for surgery, we managed patients with a combination of broad-spectrum antibiotics. If surgery was indicated, we gave antibiotics after cultures were obtained intraoperatively. In these cases, IV broad-spectrum antibiotics were given until the culture and sensitivity findings were available, and then the antibiotics were adjusted accordingly. Double IV antibiotics with good bone penetration were generally recommended for 6 weeks; however, this duration was longer for TB and brucellosis patients. We refer the reader to the review by Gouliouris et al. for detailed antibiotic options and dosages according to the causative organism. ${ }^{13}$ The patient needs to know that they must comply with the treatment and avoid any interruption of the antibiotic course in order to prevent any infectious flare-ups or recurrences.

Generally, surgery is considered the treatment of choice in cases of an epidural collection compressing the spinal cord or nerve roots, progressive or acute neurological deficit, evidence of spinal instability or deformity, and un- 
Waheed et al.

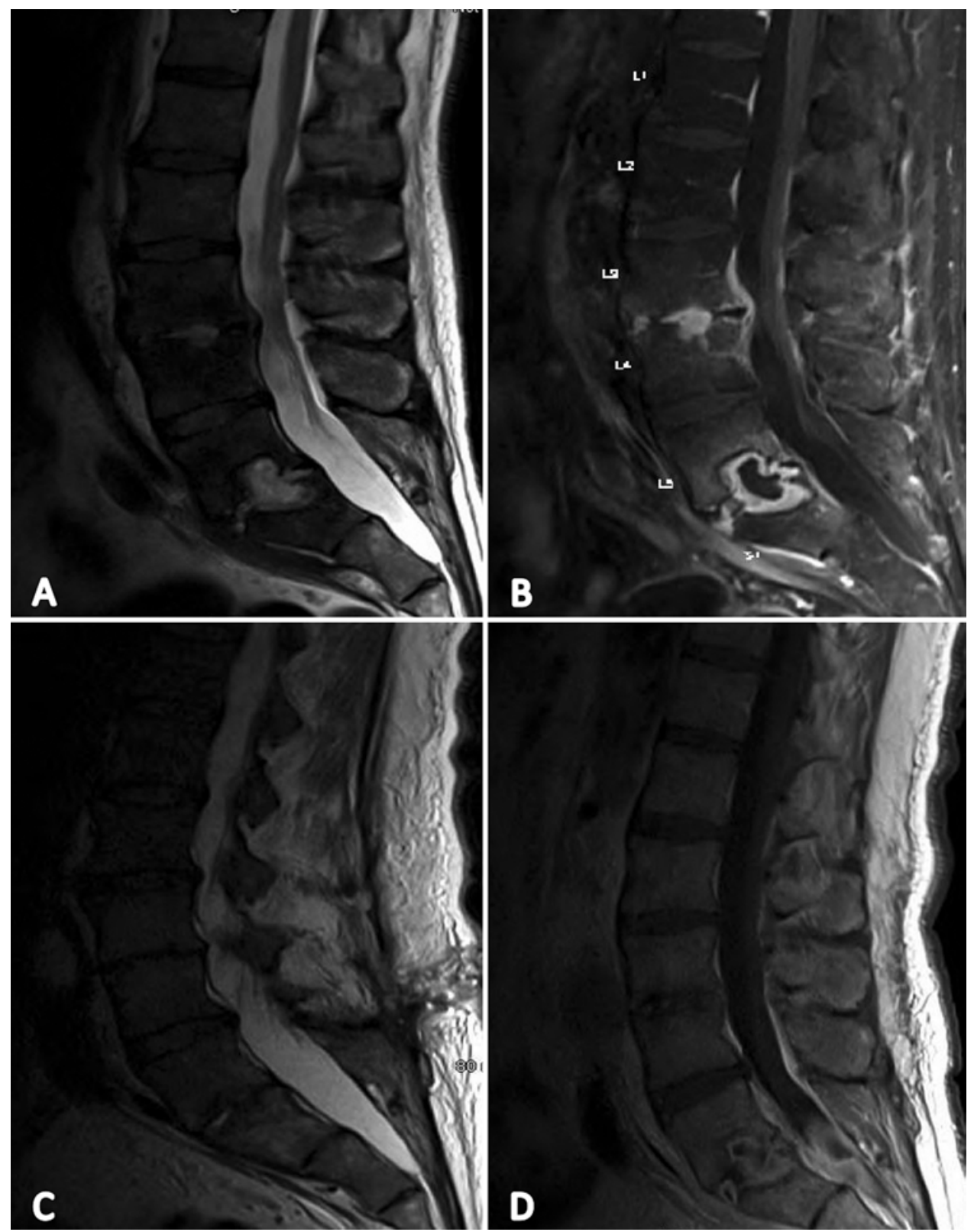

FIG. 2. Sagittal MRI studies of the thoracic spine with and without contrast obtained in a patient with S. aureus spondylodiscitis. A: Preoperative T2-weighted sequence showing high-intensity signal in the L3-4 and L5-S1 disc space and surrounding inflammatory changes in the adjacent vertebrae and destruction of the adjacent plates at L5 and S1. B: Preoperative T1-weighted sequence with contrast showing ring enhancement with central cavitation in the disc space and adjacent vertebral bodies. C and D: Sixmonth postoperative T2- and T1-weighted sequences with contrast showing improvement of the inflammatory changes in the disc space and adjacent vertebral bodies.

manageable severe back pain. This avoids extended bed rest, which in turn leads to complications related to a lack of muscle activity such as DVT and disuse muscle atrophy, ${ }^{6,8,14,29}$ Our primary objectives during surgery were to take cultures, evacuate pus, and debride devitalized tissue. This is consistent with the Tschöke et al. experience, which suggests that moderate debridement, connection of deep purulent spaces to the surface, and administration of appropriate antibiotics can achieve a cure. ${ }^{33}$ In our series, 2 patients required fusion surgery after laminectomy because of uncontrollable pain. Although open surgery has been the technique of choice traditionally, new publications refer to endoscopic ${ }^{7}$ and minimally invasive ${ }^{34}$ techniques for spondylodiscitis management.

Contrary to findings in the literature, we believe that using metal (titanium screws and rods) in the fixation does not prevent an infection cure or increase the risk of superinfection in all cases (TB, brucellosis, and other bacteria). This was confirmed by the recent review of 118 spinal infection patients by Bydon et al., who compared decompression surgery versus instrumentation in terms of repeat surgery and infection persistence. ${ }^{3}$ In our series, patients treated with 


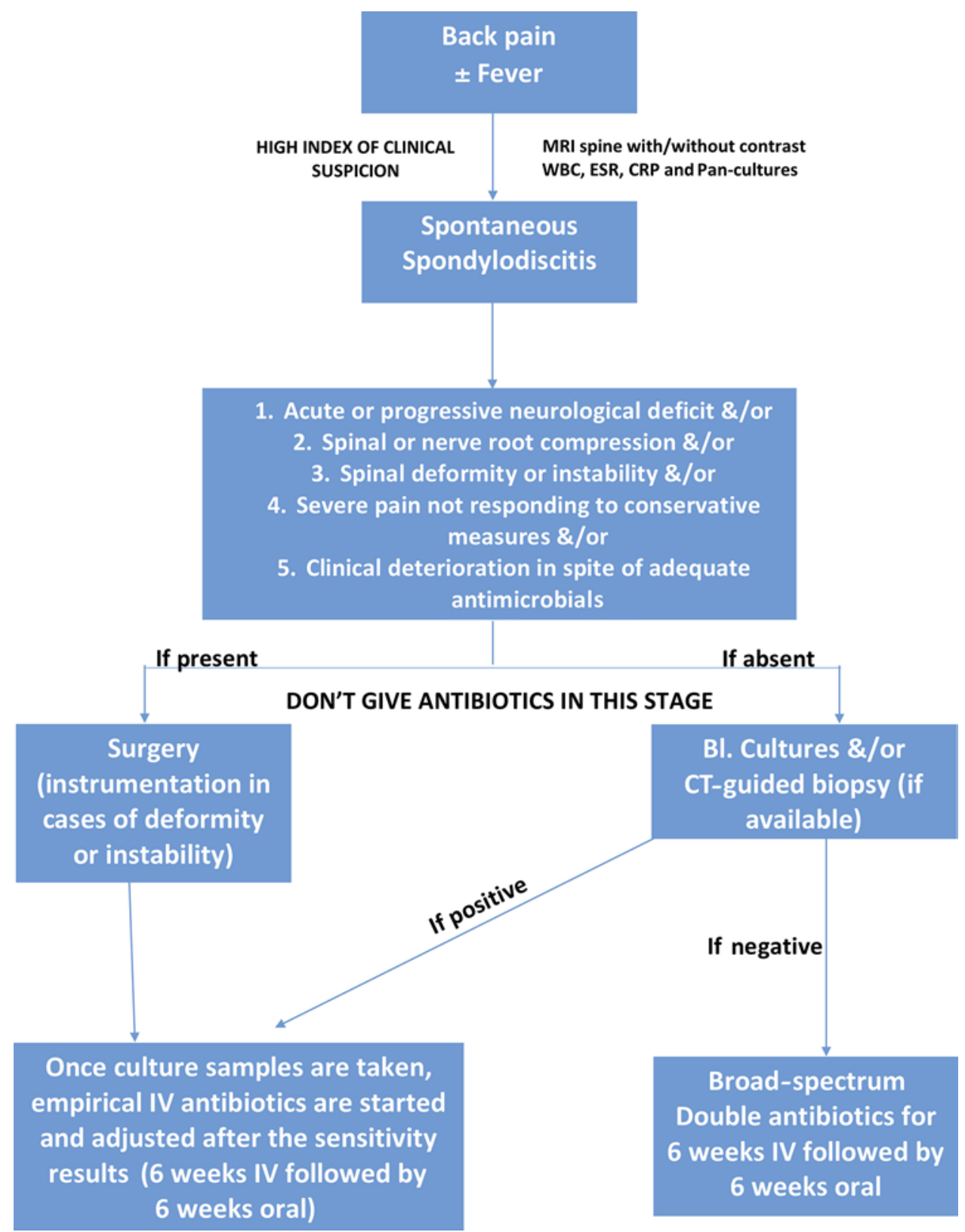

FIG. 3. Proposed management algorithm. BI. = blood.

internal fixation had significant pain improvement postsurgery with early mobilization, compared to the outcome in patients treated conservatively or with decompression.

\section{Study Limitations}

Among the limitations of this study is the lack of diversity in approaches to the spine, e.g., anterior approaches. Also, there was no cervical spondylodiscitis admission during the study period. Neither was there an interventionist who could perform CT-guided biopsy of the infection for pathological analysis and early diagnosis of the pathogen.

\section{Lessons Learned}

1. If surgery is indicated, avoid giving preoperative antibiotics in order to get positive cultures.
2. The key to infection cure is prolonged antibiotics treatment.

3. The most important indicators of successful management are clinical improvement and a decrease in CRP levels.

4. The use of instrumentation, especially titanium, does not affect the infection cure.

5. We propose an algorithm that can help in the future management of spondylodiscitis (Fig. 3).

\section{Conclusions}

The incidence of spondylodiscitis is progressively rising due to the availability of more efficient imaging and the increase in vulnerable patients. A high suspicion index is needed for early diagnosis and management of this 
disease. The ideal treatment for spondylodiscitis is still a matter of controversy. In our experience, surgery was not indicated in all cases, and conservative treatment with broad-spectrum antibiotics still had a role in the management of spondylodiscitis. However, spinal decompression and instrumentation was indicated in most of the patients with tuberculous disease, instability, or deformity. Moreover, in our experience, using titanium instrumentation did not increase the risk of superinfection or resistance to antimicrobials. Prospective, multicenter randomized trials are needed to set guidelines for the treatment of spontaneous spondylodiscitis.

\section{References}

1. Antunes JL: Infections of the spine. Acta Neurochir (Wien) 116:179-186, 1992

2. Butler JS, Shelly MJ, Timlin M, Powderly WG, O'Byrne JM: Nontuberculous pyogenic spinal infection in adults: a 12-year experience from a tertiary referral center. Spine (Phila Pa 1976) 31:2695-2700, 2006

3. Bydon M, De la Garza-Ramos R, Macki M, Naumann M, Sciubba DM, Wolinsky JP, et al: Spinal instrumentation in patients with primary spinal infections does not lead to greater recurrent infection rates: an analysis of 118 cases. World Neurosurg 82:e807-e814, 2014

4. Cahill DW, Love LC, Rechtine GR: Pyogenic osteomyelitis of the spine in the elderly. J Neurosurg 74:878-886, 1991

5. Carragee EJ, Kim D, van der Vlugt T, Vittum D: The clinical use of erythrocyte sedimentation rate in pyogenic vertebral osteomyelitis. Spine (Phila Pa 1976) 22:2089-2093, 1997

6. Castilla JM, Martín V, Rodríguez-Salazar A: [Surgical treatment of patients with spinal infection.] Neurocirugia (Astur) 13:101-109, 2002 (Span)

7. Chen HC, Huang TL, Chen YJ, Tsou HK, Lin WC, Hung $\mathrm{CH}$, et al: A minimally invasive endoscopic surgery for infectious spondylodiscitis of the thoracic and upper lumbar spine in immunocompromised patients. BioMed Res Int 2015:780451, 2015

8. Chen WH, Jiang LS, Dai LY: Surgical treatment of pyogenic vertebral osteomyelitis with spinal instrumentation. Eur Spine J 16:1307-1316, 2007

9. Devkota P, Krishnakumar R, Renjith Kumar J: Surgical management of pyogenic discitis of lumbar region. Asian Spine J 8:177-182, 2014

10. Duarte RM, Vaccaro AR: Spinal infection: state of the art and management algorithm. Eur Spine J 22:2787-2799, 2013

11. Fantoni M, Trecarichi EM, Rossi B, Mazzotta V, Di Giacomo G, Nasto LA, et al: Epidemiological and clinical features of pyogenic spondylodiscitis. Eur Rev Med Pharmacol Sci 16 (Suppl 2):2-7, 2012

12. Flamm ES: Percivall Pott: an 18th century neurosurgeon. J Neurosurg 76:319-326, 1992

13. Gouliouris T, Aliyu SH, Brown NM: Spondylodiscitis: update on diagnosis and management. J Antimicrob Chemother 65 (Suppl 3):iii11-iii24, 2010

14. Guerado E, Cerván AM: Surgical treatment of spondylodiscitis. An update. Int Orthop 36:413-420, 2012

15. Hsieh PC, Wienecke RJ, O’Shaughnessy BA, Koski TR, Ondra SL: Surgical strategies for vertebral osteomyelitis and epidural abscess. Neurosurg Focus 17(6):E4, 2004

16. Kang BU, Lee SH, Ahn Y, Choi WC, Choi YG: Surgical site infection in spinal surgery: detection and management based on serial C-reactive protein measurements. J Neurosurg Spine 13:158-164, 2010

17. Kim CJ, Song KH, Jeon JH, Park WB, Park SW, Kim HB, et al: A comparative study of pyogenic and tuberculous spondylodiscitis. Spine (Phila Pa 1976) 35:E1096-E1100, 2010

18. Kothari MK, Shah KC, Tikoo A, Nene AM: Surgical management in elderly patients with tuberculous spondylodiscitis: ten year mortality audit study. Asian Spine J 10:915-919, 2016

19. Kulowski J: Pyogenic osteomyelitis of the spine: an analysis and discussion of 102 cases. J Bone Joint Surg Am 18:343364, 1936

20. Lee KY: Comparison of pyogenic spondylitis and tuberculous spondylitis. Asian Spine J 8:216-223, 2014

21. Livorsi DJ, Daver NG, Atmar RL, Shelburne SA, White AC Jr, Musher DM: Outcomes of treatment for hematogenous Staphylococcus aureus vertebral osteomyelitis in the MRSA ERA. J Infect 57:128-131, 2008

22. Martín-Alonso J, Delgado-López PD, Castilla-Díez JM, Martín-Velasco V, Galacho-Harriero AM, Ortega-Cubero S, et al: [Role of surgery in spontaneous spondylodiscitis: Experience in 83 consecutive patients.] Neurocirugia (Astur) 29:64-78, 2018 (Span)

23. Mohamed AS, Yoo J, Hart R, Ragel BT, Hiratzka J, Hamilton DK, et al: Posterior fixation without debridement for vertebral body osteomyelitis and discitis. Neurosurg Focus 37(2):E6, 2014

24. Moore SL, Rafii M: Imaging of musculoskeletal and spinal tuberculosis. Radiol Clin North Am 39:329-342, 2001

25. Patel SS, Aruni W, Inceoglu S, Akpolat YT, Botimer GD, Cheng WK, et al: A comparison of Staphylococcus aureus biofilm formation on cobalt-chrome and titanium-alloy spinal implants. J Clin Neurosci 31:219-223, 2016

26. Pellisé F: Tuberculosis and Pott's disease, still very relevant health problems. Eur Spine J 22 (Suppl 4):527-528, 2013

27. Perronne C, Saba J, Behloul Z, Salmon-Céron D, Leport C, Vildé JL, et al: Pyogenic and tuberculous spondylodiskitis (vertebral osteomyelitis) in 80 adult patients. Clin Infect Dis 19:746-750, 1994

28. Rath SA, Neff U, Schneider O, Richter HP: Neurosurgical management of thoracic and lumbar vertebral osteomyelitis and discitis in adults: a review of 43 consecutive surgically treated patients. Neurosurgery 38:926-933, 1996

29. Rezai AR, Woo HH, Errico TJ, Cooper PR: Contemporary management of spinal osteomyelitis. Neurosurgery 44:10181026, 1999

30. Shetty AP, Aiyer SN, Kanna RM, Maheswaran A, Rajasekaran S: Pyogenic lumbar spondylodiscitis treated with transforaminal lumbar interbody fusion: safety and outcomes. Int Orthop 40:1163-1170, 2016

31. Shiban E, Janssen I, Wostrack M, Krieg SM, Horanin M, Stoffel M, et al: Spondylodiscitis by drug-multiresistant bacteria: a single-center experience of 25 cases. Spine J 14:2826-2834, 2014

32. Shousha M, Heyde C, Boehm H: Cervical spondylodiscitis: change in clinical picture and operative management during the last two decades. A series of 50 patients and review of literature. Eur Spine J 24:571-576, 2015

33. Tschöke SK, Fuchs H, Schmidt O, Gulow J, von der Hoeh NH, Heyde CE: Single-stage debridement and spinal fusion using PEEK cages through a posterior approach for eradication of lumbar pyogenic spondylodiscitis: a safe treatment strategy for a detrimental condition. Patient Saf Surg 9:35, 2015

34. Turel MK, Kerolus M, Deutsch H: The role of minimally invasive spine surgery in the management of pyogenic spinal discitis. J Craniovertebr Junction Spine 8:39-43, 2017

35. Valancius K, Hansen ES, Høy K, Helmig P, Niedermann $\mathrm{B}$, Bünger $\mathrm{C}$ : Failure modes in conservative and surgical management of infectious spondylodiscitis. Eur Spine J 22:1837-1844, 2013

36. Yang SC, Fu TS, Chen HS, Kao YH, Yu SW, Tu YK: Mini- 
mally invasive endoscopic treatment for lumbar infectious spondylitis: a retrospective study in a tertiary referral center. BMC Musculoskelet Disord 15:105, 2014

37. Zarrouk V, Feydy A, Sallès F, Dufour V, Guigui P, Redondo A, et al: Imaging does not predict the clinical outcome of bacterial vertebral osteomyelitis. Rheumatology (Oxford) 46:292-295, 2007

38. Zimmerli W: Clinical practice. Vertebral osteomyelitis. $\mathbf{N}$ Engl J Med 362:1022-1029, 2010

39. Zimmerli W, Widmer AF, Blatter M, Frei R, Ochsner PE: Role of rifampin for treatment of orthopedic implant-related staphylococcal infections: a randomized controlled trial. JAMA 279:1537-1541, 1998

\section{Disclosures}

The authors report no conflict of interest concerning the materials or methods used in this study or the findings specified in this paper.

\section{Author Contributions}

Conception and design: all authors. Acquisition of data: Waheed. Analysis and interpretation of data: Soliman, Ali, Aly. Drafting the article: Waheed. Critically revising the article: all authors. Reviewed submitted version of manuscript: all authors. Approved the final version of the manuscript on behalf of all authors: Soliman. Study supervision: Ali, Aly.

\section{Supplemental Information \\ Videos}

Video Abstract. https://vimeo.com/304187182.

\section{Correspondence}

Mohamed A. R. Soliman: Cairo University, Cairo, Egypt. moh.ar.sol@kasralainy.edu.eg. 